\title{
Evaluation of Health-Related Physical Fitness Profiles of Turkish Students in Urban and Rural School Districts
}

\author{
Gökhan Umutlư ${ }^{1}$, Nasuh Evrim Acar ${ }^{1}$ and Yağmur Akkoyunlu ${ }^{2}$ \\ ${ }^{1}$ Mersin University, School of Physical Education and Sport, Turkey \\ ${ }^{2}$ Dumlupinar University, School of Physical Education and Sport, Turkey \\ *Corresponding author: gokhanumutlu@ mersin.edu.tr
}

\begin{abstract}
Physical fitness (PF) is an important element for overall health. The scope of the current study was to investigate the level of physical fitness of 12-14 aged students in urban and rural school districts and it's relation to the rate of physical activity participation. A total of 214 students (100 boys and 114 girls) were enrolled in this research, respectively. PF was assessed using five tests from the Fitnessgram Test Battery. According to Fitnessgram health-related fitness standards the prevalence of percent body fat (NI-Health Risk: $22.8 \%$ vs. $11.5 \%$; NI: $43.3 \%$ vs. 19.5 ; HFZ: $33.1 \%$ vs. $69.0 \%$; Very Lean: $0.8 \%$ vs. $0 \%$ ); BMI (NI-Health Risk: $4.7 \%$ vs. $2.3 \%$; NI: $17.3 \%$ vs. $5.7 \%$; HFZ: $67.7 \%$ vs. $78.2 \%$; Very Lean: $10.2 \%$ vs. $13.8 \%$ ) and VO2max (NI: $12.6 \%$ vs. $0 \%$; HFZ: $87.4 \%$ vs. $100 \%$ ) were found in the overall sample in urban and rural school districts, respectively. As stated in Kruskal-Wallis $\mathrm{H}$ test results, the students in the urban school districts had significantly higher body weight $\left(x^{2}(1)=20.44, \mathrm{p}=0,000\right)$, percent body fat $\left(x^{2}(1)=20.49, \mathrm{p}=0.000\right), \operatorname{BMI}\left(x^{2}(1)=15.45, \mathrm{p}=0.000\right)$ and significantly lower VO2max $\left(x^{2}(1)=11.21, \mathrm{p}=0.001\right)$, curl-ups $\left(x^{2}(1)=54.77, \mathrm{p}=0.000\right), 90^{\circ}$ push-ups $\left(x^{2}(1)=5.09, \mathrm{p}=0.024\right)$ and PA participation rates $\left(x^{2}(1)=85.02, \mathrm{p}=0.000\right)$ compared to counterparts in the rural school districts. In conclusion, the physical activity participation levels of the overall students were positively associated with the school district, VO2max, curl-up, and push-up. However, it was negatively correlated with body weight, percent body fat, and BMI in urban and rural school districts.
\end{abstract}

\section{Keywords}

Fitnessgram, physical fitness, exercise, youth, body mass index

\section{INTRODUCTION}

Physical fitness refers to the ability of the heart, lungs, blood vessels and muscles to function at their optimum efficiency (Graham et al., 2001). A sedentary lifestyle has become increasingly common among children in recent years and results in many health-related problems. It has been stated that the activity level of the children living in the urban is lower than those in the previous studies, and it is stated that broader research is needed in the rural areas (Meredith and Welk, 2010). Criterion-referenced fitness evaluation standards are more valid and useful since they enable the individuals to compare their overall fitness status to an absolute criterion. Fitnessgram is a comprehensive evaluation program developed by Cooper Institute in 1982 to determine the physical activity levels of students. This fitness program regularly monitors the gender, age, etc., depending on the factor of participation in physical activity and aims to improve the sensory, cognitive and behavioral characteristics of children and adolescents, regardless their differences (Sharon et al., 2006). Fitnessgram program helps parents and students to understand the importance of physical activity. It also enables parents and administrators to create detailed reports for the students and give them responsibility for conducting their own activities and taking their own records using Fitnessgram test-battery (Meredith and Welk, 2010).

The aim of the program is to guide the students to take a lifelong habit of participating in physical activities (Sharon et al., 2006). Fitnessgram is a comprehensive youth fitness program that includes a variety of fitness assessments and is divided into sub-units to evaluate the physical and physiological characteristics of the participants in 
terms of aerobic capacity, body composition, muscular strength, endurance and flexibility (Ortega et al.,2008). The results obtained are compared with the HFZ (Healthy Fitness Zone) reference scores to determine the student's physical fitness and to report on the student's status. The testing parameters of children are used not to compare with each other but to see their own physical fitness status and to determine the level of activity required to achieve standard values.

This practical evaluation standards help to place the individual in three FITNESSGRAM ${ }^{\circledR}$ health-related fitness categories which are determined based on age and sex-specific cut-off points of the Fitnessgram 10.0 criteria: Healthy Fitness Zone (HFZ), Needs Improvement (NI), and Needs Improvement-Health Risk (NI-HR). The participants who are considered to be at a low risk for developing metabolic syndrome are placed in the HFZ or are classified either in NI or NI-HR zones. Outcome measures classified in NI or NIHR zones reflect the students do not meet FITNESSGRAM ${ }^{\circledR}$ health-related fitness standards (Susan et al.,2017) and are considered to be at a higher risk for developing metabolic syndrome (Meredith and Welk, 2010).

By taking the physical characteristics of the urban or rural contexts that influence health and well-being into consideration the scope of this study was to compare the physical and physiological characteristics of secondary school students in urban and rural school districts in Kütahya and to determine whether the rate of physical activity participation affect the outcomes.

\section{MATERIALS AND METHODS}

\section{Body Composition}

Triceps and calf skinfold thicknesses were measured to calculate percent body fat. The triceps skinfold was measured on the back of the right arm over the triceps muscle, midway between the elbow and the acromion process of the scapula. Additionally, to measure calf skinfold the right foot was placed flat on an elevated surface with the knee flexed at a $90^{\circ}$ angle and was measured on the inside of the right leg at the level of maximal calf girth. The Slaughter-Lohman equation (Slaughter et al., 1988) was used to predict percent body fat both for boys $(0.735$ (Triceps + Calf $)+$
1.0) and girls $(0.735$ (Triceps + Calf $)+1.0$, Girls: $\%$ Body Fat $=0.610$ (Triceps + Calf $)+5.1)$. Each measurement was taken three times, with the recorded score being the median (middle) value of the three scores and each reading was recorded to the nearest .5 millimeters.

\section{Aerobic Capacity}

A 20-meters Progressive Aerobic Cardiovascular Endurance Run (PACER) was used to evaluate cardiorespiratory fitness (CFR) (Plowman, 2014) in which students run across the 20-m laps and touch the line with a foot by the time the beep (e.g., the PACER cadence) sounds. For this test, a calibrated cassette with increments of $0.5 \mathrm{~km} / \mathrm{h}$ in each minute of signal intervals, and an individual score sheet was used to record the number of laps completed. The children were asked to turn around and run back to the other end at the sound of the beep. At the first minute of the test, the running speed was slow and the children were told not to run fast and they were given 9 seconds to run each lap. In case of some students get to the line before the beep, they were told to wait for the beep before running to the other direction. Students continued running until they failed to reach the line before the beep for the second time. All students were informed about a single beep will sound at the end of the time for each lap and a triple beep sound at the end of each minute. Thus, the triple beep served the same function as the single beep and also altered the runners that the pace will get faster. All students were asked not to stop but should continue the test by turning and running toward the other end of the area when the triple beep sounds. The values obtained were compared with HFZ (Healthy Fitness Zone) aerobic capacity reference values for control purposes. Peak Oxygen Consumption (VO2peak) was computed using the following equation: $\dot{V} O 2$ peak $=0.353$ (Laps) -1.121 (Age)+ 45.619. Each child's VO2peak value was then compared to sex-and-age-specific standards. After completion of the test, each student continued to walk and stretch in the designated cool-down area.

\section{Abdominal Strength And Endurance Curl-Up}

Following a brief instruction, participants were divided into different groups and an 
administrator were assigned to each group to control and count the numbers of curl-ups completed. All students were told that the movement should be slow and gauged to the specified cadence of about 20 curl-ups per minute ( 1 curl every 3 seconds). The administrator used a prerecorded cadence to ensure accurate testing for students. First, each student from the different groups lied in a supine position on the mat, knees were bent at an angle of approximately $140^{\circ}$, feet flat on the floor, legs were held slightly apart, arms straight and parallel to the trunk with palms of the hands resting on the mat. The fingers were stretched out and the head was in contact with the mat. All students were told to extend their feet as far as possible from the buttocks while still allowed their feet to remain flat on the floor. After the correct position was enhanced, a measuring strip was placed on the mat under the student's legs at which the fingertips of the participant were just resting on the nearest edge of the measuring strip. All participants curled-up until they can no longer continue or had completed up to a maximum of 75 curl-ups at a specified pace.

\section{Trunk Extensor Strength And Flexibility Trunk Lift}

In the assessment of trunk extensor strength and flexibility of the students, a mat was placed on the ground and each participant laid down on the mat in a prone position (facedown). To enhance the proper alignment prior to movement toes were pointed and hands were placed under the thighs and a marker was placed on the floor in line with the student's eyes, subsequently. All students were told to focus on the marker during the entire test. After the information process, the students were asked to lift their upper body off the floor, in a very slow and controlled manner, to a maximum height of 12 inches. The testing administrator warned the participants when they were not able to maintain their head in a neutral (straight) alignment with the spine. After the position was held long enough to allow the tester to place the ruler on the floor in front of the student and the tester determined the distance from the floor to the student's chin. After completion of the measurement, the student returned to the starting position in a controlled manner. The highest score in two trials was then recorded on the score sheet.

\section{Upper Body Strength And Endurance $90^{\circ}$ Push- Up}

One administrator observed the students while they perform the test and the other administrator counted $90^{\circ}$ push-ups and watched to see that the student being tested bends the elbow to $90^{\circ}$ with the upper arm parallel to the floor.

Prior to the testing session, all students were told to take a prone position on the mat with hands placed under or slightly wider than the shoulders, fingers stretched out, legs straight and slightly apart, and toes tucked under. Afterward, the students started to push up off the mat with their arms until the arms are straight, keeping the legs and back straight. The whole students were asked to keep their back in a straight line from head to toes throughout the test. The student then lowered his/her body using the arms until the elbows bend at a $90^{\circ}$ angle and the upper arms are parallel to the floor. During the test, all administrators were told to maintain a rhythm which should be approximately $2090^{\circ}$ push-ups per minute or 1 $90^{\circ}$ push-up every 3 seconds until the students fail to achieve the proper form of the movement or could not keep his/her arms straight while pushesup.

\section{Flexibility Back-Saver Sit And Reach}

The modified-back-saver-sit-and-reach test was used to evaluate flexibility. All students were asked to sit with one knee bent and one leg straight against a box and reach forward testing one leg at a time. During the measurement, one leg was fully extended with the foot flat against the face of the box. The other knee was bent with the sole of the foot flat on the floor. The instep was placed in line with, and 2 to 3 inches to the side of, the straight knee. The arms were extended forward over the measuring scale with the hands placed one on top of the other. Throughout the test, students were asked to keep their back straight and the head up. Prior to the performance, all students placed their hands with palms down and reached directly forward with both hands along the scale four times and held the position of the fourth reach for at least 
1 second. After one side was measured, the student switched the position of the legs and reached again. The number of inches on each side to the nearest $1 / 2$ inch reached, to a maximum score of 12 inches was recorded and compared to Healthy Fitness Zone to determine whether the students meet the standard on both the right and left sides.

\section{Statistical Analysis}

Descriptive data are presented as means and standard deviation unless otherwise stated. All variables were checked for normality and they were not normally distributed. A non-parametric Kruskal-Wallis $\mathrm{H}$ test was used to test the physical fitness and physiological profiles among urban and rural schools and Mann-Whitney U tests were used to determine intergroup differences in data analysis. The level of significance was set at $p \leq 0.05$. Correlation between the physical activity (PA) participation rate and physical-physiological profiles were tested using the Pearson product moment correlation coefficient.

\section{RESULTS}

Descriptive characteristics of the participants in urban and rural school districts were presented as Mean \pm SD. Both boys and girls in urban school districts had higher height, weight, BMI, body fat compared to counterparts in rural school districts $(\mathrm{p}<0.001$ for all).

Table 1. Mean, standard deviations (SD) of physical and physiological profiles in Urban school districts

\begin{tabular}{lccc}
\hline & 6th Grade & 7th Grade & 8th Grade \\
\hline n & 49 & 53 & 25 \\
\hline Age $($ years) & $12.06 \pm 0.24$ & $13.08 \pm 0.27$ & $14.00 \pm 0.00$ \\
\hline Height $(\mathrm{cm})$ & $150.14 \pm 7.70$ & $154.21 \pm 7.89$ & $161.00 \pm 6.40$ \\
\hline Weight $(\mathrm{kg})$ & $43.37 \pm 9.63$ & $49.13 \pm 10.82$ & $51.96 \pm 9.28$ \\
\hline BMI & $19.11 \pm 3.35$ & $20.55 \pm 3.76$ & $20.14 \pm 3.99$ \\
\hline Body Fat Percentage $(\%)$ & $28.79 \pm 9.41$ & $27.32 \pm 8.65$ & $33.66 \pm 9.47$ \\
\hline PA Participation Rates (hours) & $11.57 \pm 7.01$ & $13.77 \pm 8.72$ & $8.12 \pm 2.37$ \\
\hline Trunk Lift (inches) & $10.10 \pm 1.92$ & $10.67 \pm 1.53$ & $8.63 \pm 1.89$ \\
\hline Back Saver Sit\&Reach (inches) & $7.22 \pm 2.43$ & $7.70 \pm 2.83$ & $5.55 \pm 1.80$ \\
\hline 90 Push-Up (reps.) & $8.31 \pm 6.32$ & $13.43 \pm 9.69$ & $7.92 \pm 6.21$ \\
\hline Curl-Up (reps.) & $17.69 \pm 12.15$ & $26.45 \pm 14.87$ & $18.92 \pm 11.93$ \\
\hline VO2max $\left(\mathrm{ml} / \mathrm{kg} / \mathrm{min}^{-1}\right)$ & $44.14 \pm 5.35$ & $47.87 \pm 5.55$ & $45.43 \pm 5.61$ \\
\hline
\end{tabular}

Table 2. Mean, standard deviations (SD) of physical and physiological profiles in Rural school districts

\begin{tabular}{lccc}
\hline & 6th Grade & 7th Grade & 8th Grade \\
\hline n & 26 & 29 & 32 \\
\hline Age (years) & $12.00 \pm 0.00$ & $13.00 \pm 0.00$ & $14.00 \pm 0.00$ \\
\hline Height $(\mathrm{cm})$ & $146.92 \pm 6.90$ & $152.55 \pm 6.17$ & $154.75 \pm 6.90$ \\
\hline Weight $(\mathrm{kg})$ & $36.54 \pm 5.84$ & $43.66 \pm 7.12$ & $44.09 \pm 7.40$ \\
\hline BMI & $16.85 \pm 1.66$ & $18.98 \pm 2.94$ & $18.38 \pm 2.59$ \\
\hline Body Fat Percentage (\%) & $21.75 \pm 9.04$ & $22.86 \pm 6.34$ & $25.39 \pm 8.99$ \\
\hline PA Participation Rates (hours) & $29.12 \pm 9.33$ & $24.45 \pm 9.86$ & $22.66 \pm 8.70$ \\
\hline Trunk Lift (inches) & $9.05 \pm 1.72$ & $10.24 \pm 1.26$ & $10.00 \pm 1.71$ \\
\hline Back Saver Sit\&Reach (inches) & $6.66 \pm 1.98$ & $7.00 \pm 1.94$ & $7.10 \pm 2.13$ \\
\hline 90' Push-Up (reps.) & $13.04 \pm 6.68$ & $12.86 \pm 6.27$ & $12.44 \pm 11.28$ \\
\hline Curl-Up (reps.) & $33.77 \pm 19.58$ & $43.76 \pm 14.87$ & $53.13 \pm 17.35$ \\
\hline VO2max (mi/kg/min ${ }^{-1}$ ) & $48.76 \pm 4.99$ & $48.51 \pm 4.87$ & $47.58 \pm 5.11$ \\
\hline
\end{tabular}


Table 3. Comparison of FITNESSGRAM Performance Standards between Urban and Rural school districts

\begin{tabular}{ccccc}
\hline & \multicolumn{2}{c}{ URBAN } & \multicolumn{2}{c}{ RURAL } \\
\hline & Mean \pm SD & Mean Rank & Mean \pm SD & Mean Rank \\
\hline Body Weight (Kg) & $47.46 \pm 10.57^{*}$ & 123.33 & $41.69 \pm 7.59^{*}$ & 84.40 \\
\hline Percent Body Fat (\%) & $29.13 \pm 9.34^{*}$ & 123.35 & $23.46 \pm 8.27^{*}$ & 84.36 \\
\hline BMI & $19.91 \pm 3.68^{*}$ & 121.27 & $18.12 \pm 2.61^{*}$ & 87.40 \\
\hline VO2max (ml.kg.min ${ }^{-1}$ ) & $45.95 \pm 5.70^{*}$ & 95.77 & $48.24 \pm 4.96^{*}$ & 124.62 \\
\hline Curl-Up (rep.) & $21.59 \pm 13.85^{*}$ & 81.58 & $44.22 \pm 21.19^{*}$ & 145.33 \\
\hline $\begin{array}{c}\text { 90 } \text { Push-Up (rep.) } \\
\text { PA Participation Rate (hours } \\
\text { per week) }\end{array}$ & $10.37 \pm 8.25^{*}$ & 99.61 & $12.76 \pm 0,01^{*}$ & 119.02 \\
\hline
\end{tabular}

The Kruskal-Wallis $\mathrm{H}$ test was used to compare the anthropometric and physiological parameters among urban and rural school districts and significant differences were found in body weight $\left(x^{2}(1)=20.44, \mathrm{p}=0,000\right)$, percent body $\operatorname{fat}\left(x^{2}(1)\right.$ $=20.49, \mathrm{p}=0.000), \operatorname{BMI}\left(x^{2}(1)=15.45, \mathrm{p}=0.000\right)$, VO2max $\left(x^{2}(1)=11.21, \mathrm{p}=0.001\right)$, curl-ups $\left(x^{2}(1)\right.$ $=54.77, \mathrm{p}=0.000)$ and $90^{\circ}$ push-ups $\left(x^{2}(1)=5.09\right.$, $\mathrm{p}=0.024)$ parameters, PA participation rates $\left(x^{2}(1)\right.$ $=85.02, \mathrm{p}=0.000)$, respectively. However, no significant difference were found in trunk lift $\left(x^{2}(1)=1.91, \mathrm{p}=0.167\right)$ and back saver sit-andreach test $\left(x^{2}(1)=0.099, \mathrm{p}=0.753\right)$. Additionally, Mann-Whitney U test results which was performed in the determination of intergroup differences indicated that $\mathrm{VO} 2 \mathrm{max}$ and PA participation rates of the girls entering the Grade-6, Grade-7 and Grade- 8 in rural schools were significantly superior compared to the counterparts in urban schools (Vo2max: $\mathrm{U}=34.00, \mathrm{Z}=-2.06, \mathrm{p}<0.05$; PA participation rates: $\mathrm{U}=8.50, \mathrm{Z}=-3.96, \mathrm{p}<0.000$ ), (Vo2max: $\quad U=109.00, \quad Z=-2.58, \quad p<0.05 ; \quad P A$ participation rates: $\mathrm{U}=42.50, \mathrm{Z}=-4.28, \mathrm{p}<0.000$ ), and (Vo2max: $\mathrm{U}=60.50, \mathrm{Z}=-3.06, \mathrm{p}<0.005$; PA participation rates: $U=12.00, Z=-4.70, p<0.000$ ), respectively. Similarly, the number of the curl-ups completed for the girls entering in Grade-7 and Grade- 8 in rural schools were also found to be significantly higher compared to the counterparts in urban school areas (Curl-up: $U=88.00, Z=-$ 3.11, $\mathrm{p}<0.005 ; \quad \mathrm{U}=1.50, \quad \mathrm{Z}=-5.01, \mathrm{p}<0.000$ ), respectively.

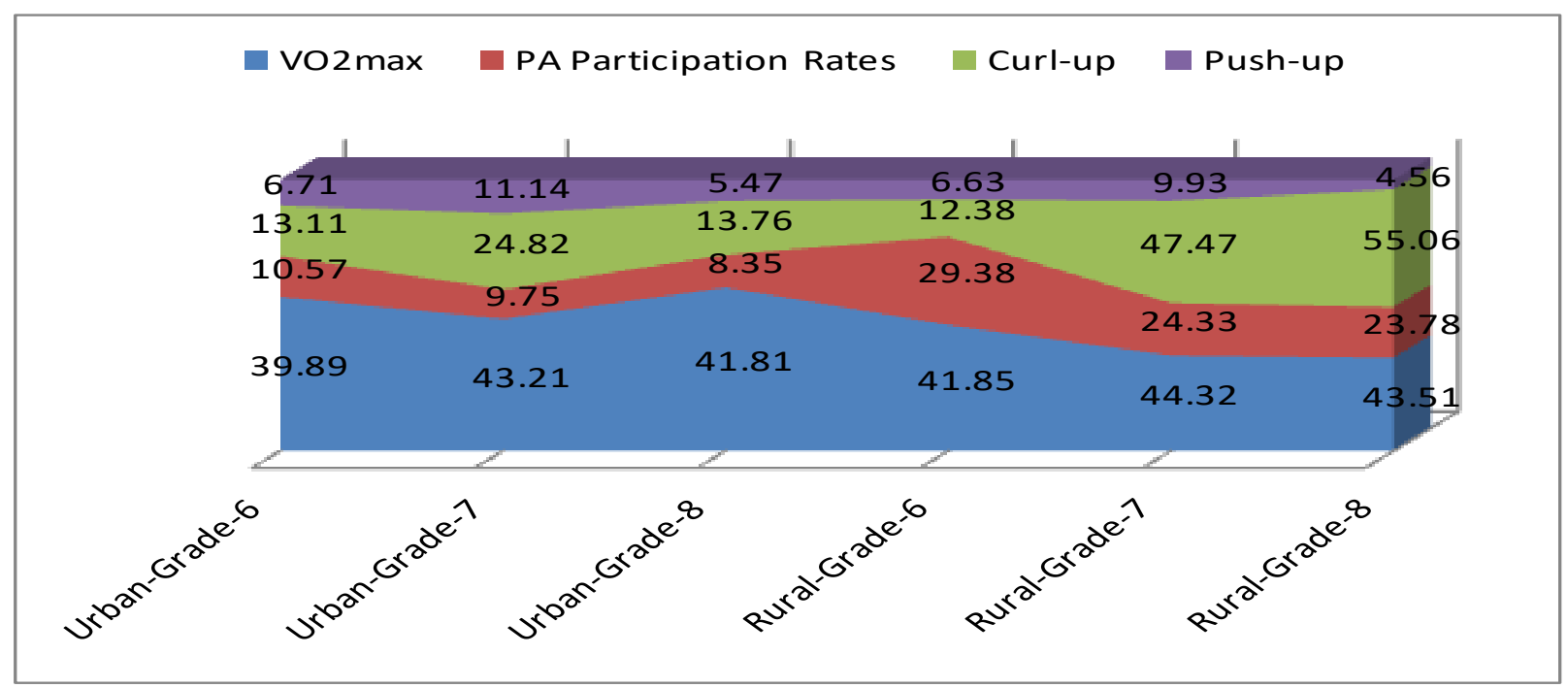

Figure 1. Mean physical and physiological profiles of girls 
On the other hand, Mann-Whitney U test results which was performed in the determination of intergroup differences indicated that VO2max, curl-up, $90^{\circ}$ modified push-up and PA participation rates of the boys entering the Grade-6 in rural schools were significantly superior compared to the counterparts in urban schools (Vo2max: $\mathrm{U}=101.00, \quad \mathrm{Z}=-2.48, \quad \mathrm{p}<0.05 ; \quad \mathrm{PA}$ participation rates: $\mathrm{U}=39.50, \mathrm{Z}=-4.24, \mathrm{p}<0.000$ ), Curl-up: $\quad \mathrm{U}=68.00, \quad \mathrm{Z}=-3.41, \mathrm{p}<0.001), \quad 90^{\circ}$ modified push-up: $U=88.50, Z=-2.84, p<0.005$ ), respectively. Similarly, the number of the curl-ups, $90^{\circ}$ modified push-up completed and PA participation rates for the boys entering in Grade- 8 in rural schools were also found to be significantly higher compared to the counterparts in urban school areas Curl-up: $U=18.00, \quad Z=-2.60$, $\mathrm{p}<0.005), \quad 90^{\circ}$ modified push-up: $\mathrm{U}=25.00, \mathrm{Z}=$ $2.13, \mathrm{p}<0.05$ ) and PA participation rates: $\mathrm{U}=2.00$, $\mathrm{Z}=-3.69, \mathrm{p}<0.000)$, respectively.

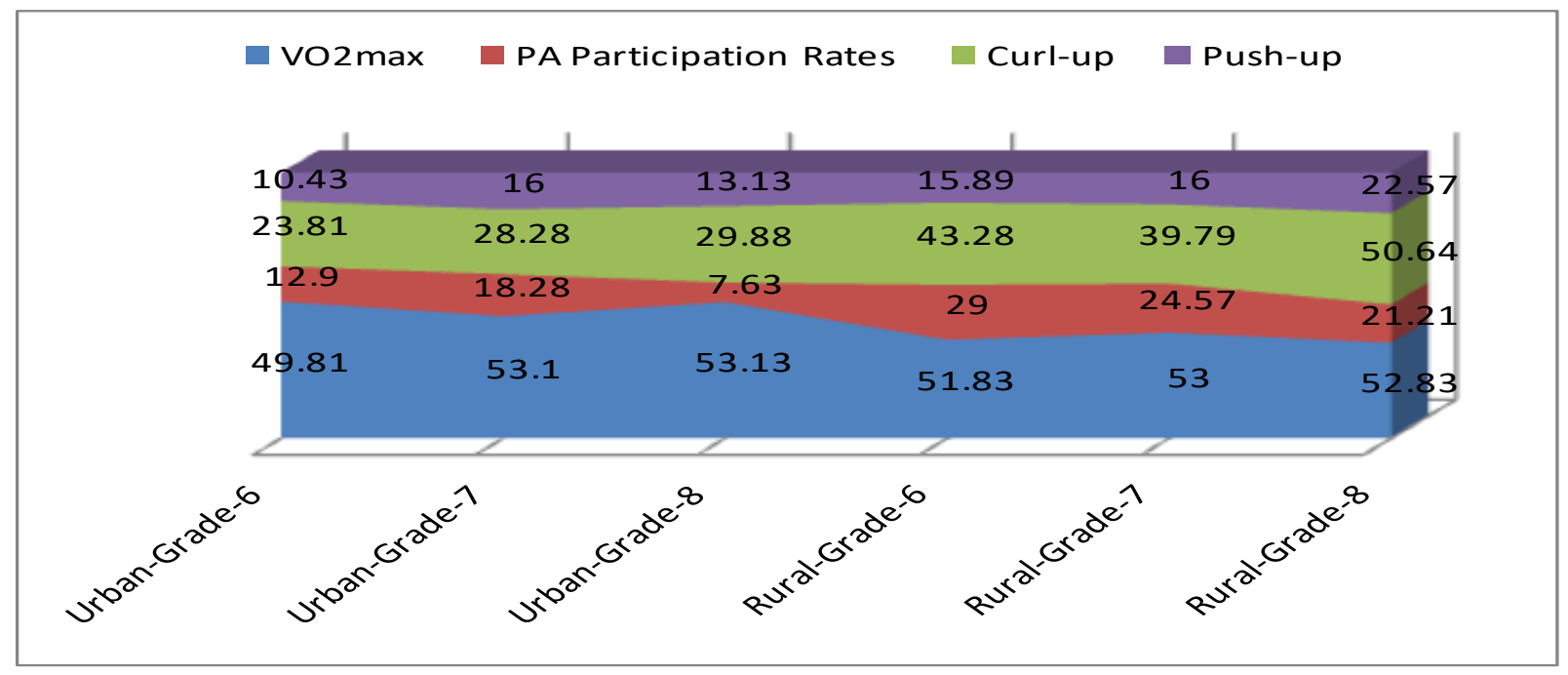

Figure 2. Mean physical and physiological profiles of girls

For each test, the physical and physiological test results were classified according to FITNESSGRAM Performance Standards and the parameters of the participants were shown below.

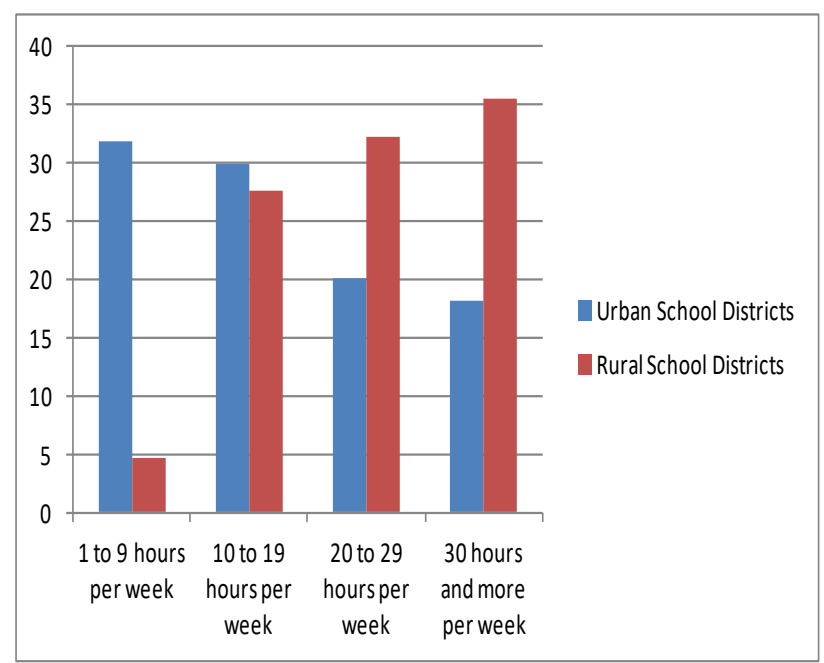

Figure 3. Physical Activity Participation Rates

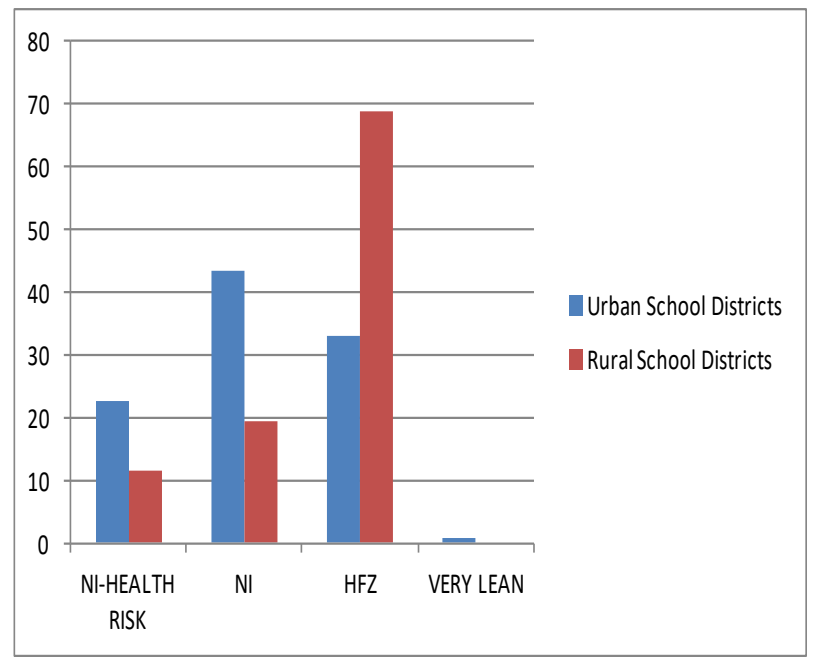

Figure 4. Fitnessgram Percent Body Fat Distribution 


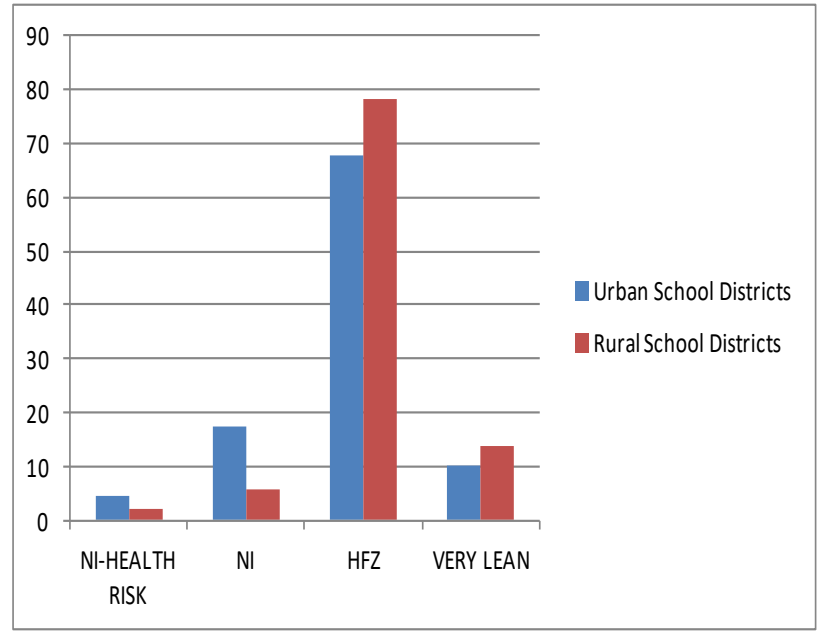

Figure 5. Fitnessgram BMI Classification

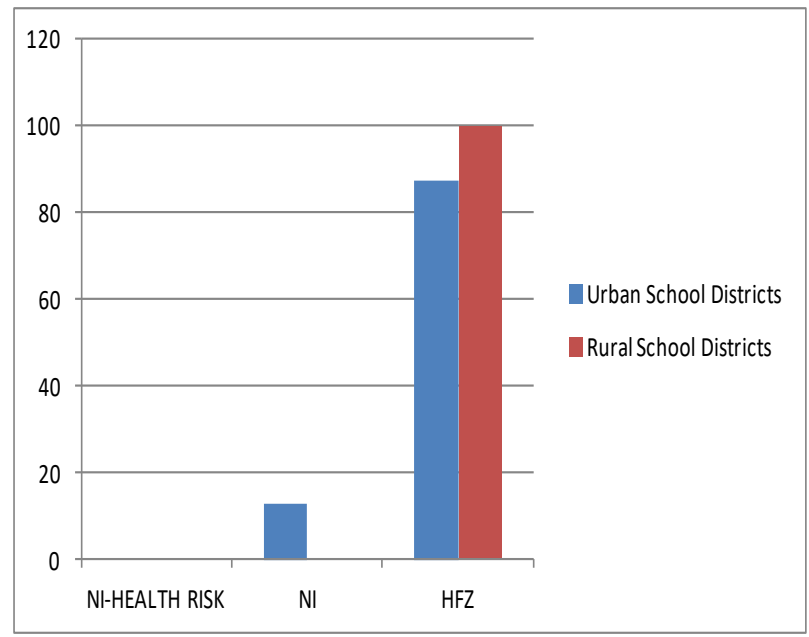

Figure 6. Fitnessgram VO2max Classification

Correlation between PA participation rate and physical-physiological profiles was tested using the Pearson product moment correlation coefficient. A positive significant correlation was found between PA participation rate and school district $(\mathrm{r}=0.619, \mathrm{p}<0.01), \mathrm{VO} 2 \mathrm{max} \quad(\mathrm{r}=0.233$, $\mathrm{p}<0.01)$, curl-up $(\mathrm{r}=0.285, \mathrm{p}<0.01), 90^{\circ}$ modified push-up $(\mathrm{r}=0.136, \mathrm{p}<0.01)$ and a negative correlation was found between PA participation rate and body weight $(\mathrm{r}=-0.213, \mathrm{p}<0.01)$, percent body fat $(\mathrm{r}=-0.263, \mathrm{p}<0.01)$, BMI $(\mathrm{r}=-0.180$, $\mathrm{p}<0.01$ ), respectively.

\section{DISCUSSION AND CONCLUSION}

The advancements in technology not only leads to a sedentary lifestyle but also changing the leisure time habits of the children. This constant development also constitutes great barriers as it could be strong enough to lead to an alteration of leisure time preferences. The FITNESSGRAM distributions presented in the preceding sections have highlighted several potential negative health hazards associated with sedentary behaviors between urban and rural school districts. Figure 1 clearly indicates the differences between physical activity tendency of the students in urban and rural school environments. As shown in Figure 1 there is a linear increase in the physical activity participation hours in rural areas. However, this rate consecutively diminished in urban schools. The lower physical activity participation rates in the urban school districts presumably resulted from the number of physical education classes administered in Grade 6, Grade-7 and Grade-8 curriculum. Besides, dietary habits of the children in urban areas, foods consumed, and the wide range of environmental factors to which the students are exposed account for an integral part of the lower rates of physical activity in urban areas. The differences between the rate of the physical activity participation patterns in urban and rural districts may also lead the children in the urban areas to maintain a sedentary lifestyle and increase the potential of cardiovascular diseases in the future.

Studies to date asserted that together with personal motivation, health and mobility issues, genetic factors, and the social and physical environments in which people live also influence on the propensity to engage in physical activity (Hamilton et al., 2007). Bundling the majority of these studies, it was reported that the insufficient rate of exercise induces a sedentary behavior which has negative health consequences and could contribute to suppressed cardiorespiratory fitness (Fanning et al., 2012). The findings of the current study were consistent with the results of the previous literature in the field. The positive correlation found between the physical activity participation rate and the environment in which students live clearly indicates the influence of this 
factor on the propensity of the children to engage in physical activity. It was stated in some studies that most of the urban areas are more likely to involve higher rates of crime and violence incidences or the access to the physical activity fields due to distance is not convenient. As a consequence of these negative conditions, many parents do not allow their children to exert physical activities in public areas due to psychological stressors which in turn demonstrates how the features of the urban areas negatively influence health and well-being of the children who live in the urban environments (Freudenberg, 2000; Geronimus, 2000).

There is a strong relationship between the development of pulmonary functions and growth of physical parameters such as height and weight. These physical parameters are further affected by nutrition and the rate of physical activities of school-aged children (Nair et al., 1997). The development of these components accounts for an integral part of improved cardiovascular, muscular strength and endurance performance capacity. The positive significant correlations found between PA participation rate and $\mathrm{VO} 2 \max$, curl-ups and $90^{\circ}$ modified push-ups and the negative correlations between PA participation rate and body weight, percent body fat and BMI in the current study strongly indicate the importance of environment on the physical activity participation rates in school-aged children. The results of the current study were found in accordance with the other studies (Hamilton et al., 2007).

The increases in the level of physical activity induce an increment in the peak expiratory flow rate which is an objective indicator of ventilatory capacity. The results of another study revealed that physical activities have a complementary impact on the growth of airway passage i.e. size and increase in strength of expiratory muscles and they reported that the children in the rural school areas had more peak expiratory flow rate than the counterparts in the urban school districts (Bandopadhyay et al., 2006). In the current study, a great deal of the students enrolling in the schools located in urban districts reported that they are attending after-school courses which presumably interfere them to participate in physical activities with their counterparts. Additionally, as most parents mainly consider the time spent for physical activity leads their children to low academic achievement and they unconsciously compromise the intellectual, social, emotional, and physical development of their children. Greenwald et al. (1996) referred to the advantages of rural schools as they are inclined to have smaller classes and the population in the classroom environment is more manageable for teachers compared to urban schools and they also reported that the achievement was greater in smaller schools with smaller classes. Correspondingly, when the results of this study were taken into consideration it is noteworthy to report that the students which are provided more assistance by their teachers in the rural schools acquired higher student achievement and liberally involve in the physical activities. On the other hand, as shown in the correlation analysis in the current study physical inactivity in the urban schools not only leads to an unhealthy society but it could also be a factor for the children to acquire lower student achievements. With this in mind, understanding the importance of the physical activity for a healthy youth is paramount.

\section{Conclusion}

The higher physical activity participation levels and lower percent body percentages and BMI rates in the rural school districts emphasize the importance of promoting and increasing regular physical activities to reduce the potential risks of health-related diseases associated with a sedentary lifestyle. Specifically, further researches are warranted in the urban school districts to quantify how much physical activity is needed to prevent and reduce the prevalence of the inactivity in those who already have classified in NI-Health Risk and NI zones according to FITNESSGRAM ${ }^{\circledR}$ health-related fitness standards.

\section{REFERENCES}

Bandopadhyay A, Basak AK, Tripathy S, Bandopadhyay P (2006). PEFR in female brickfield workers of West Bengal India. Ergonomics, 18(1):22-7.

Fanning J, Mullen SP, McAuley E (2012). Increasing Physical Activity with mobile devices: A Meta-Analysis. J Med Internet Res. 14(6):e161 
Freudenberg N (2000). Time for a national agenda to improve the health of urban populations. Am J Public Health, 90:837-840.

Geronimus AT (2000). To mitigate, resist, or undo: addressing structural influences on the health of urban populations. Am J Public Health, 90:867-872.

Graham G, Hale SA, Parker M (2001). Children moving: a reflective approach to teaching physical education. Mountain View, California, Mayfield Publishing Company.

Greenwald R, Hedges LV \& Laine RD (1996). The Effect of School Resources on Student Achievement. Review of Educational Research, 66(3), 361-372.

Hamilton MT, Hamilton DG, Zderic TW (2007). Role of low energy expenditure and sitting in obesity, metabolic syndrome, type 2 diabetes, and cardiovascular disease. Diabetes, 56:2655-2667.

Meredith MD \& Welk GJ (2010). Fitnessgram ${ }^{\circledR} /$ Activitygram ${ }^{\circledR}$ Test

Administration Manual (4th Ed.), Champaign, IL: Human Kinetics, 3-4.

Nair RH, Kesavachandran C, Sanil R, Sreekumar R, Shashidhar S (1997). Prediction equation for lung functions in South Indian children. Indian J Physiol Pharmacol, 41(4):390-6.

Ortega FB, Ruiz JR, Castillo MJ, Sjostrom M (2008). Physical fitness in childhood and adolescence: a powerful marker of health. Int J Obes, 32:1-11.

Plowman SA, Sterling CL, Corbin CB, Meredith MD, Welk GJ \& Morrow JR (2006). The History of FITNESSGRAM®. Journal of Physical Activity \& Health, 3(Suppl.2), S5S20.

Plowman SA (2014). Top 10 research questions related to musculoskeletal physical fitness testing in children and adolescents. Research Quarterly for Exercise and Sport, 85: 174187.

Racettea SB, Uhricha ML, Whitec ML, Liyang Y.B., Clarka, Ruth. (2017) Sex differences in FITNESSGRAM ${ }^{\circledR}$ health risk based on aerobic capacity and body composition among urban public elementary school children. Preventive Medicine, 103:56-59.

Slaughter MH, Lohman TG, Boileau RA, Horewill CA, Stillman RJ, VanLoan MD, Bemben
DA (1988). Skinfold equations for estimation of body fatness in children and youth. Hum Biol, 60: 709-723. 